Homer CSE, Turkmani S, Rumsey M. (2017) The State of Midwifery in small island nations of the South Pacific. Women and Birth 30 (3): 193 - 199.

\title{
THE STATE OF MIDWIFERY IN SMALL ISLAND NATIONS OF THE SOUTH PACIFIC
}

\section{Statement of Significance}

\section{Problem}

Little is known about the education, regulation and professional associations for midwives in the small island nations of the South Pacific.

What is already known?

Consistent data are available for only two of the small island nations of South Pacific countries - Papua New Guinea and Solomon Islands.

What this paper adds?

There is significant variation across the small island nations of the South Pacific in education and regulation and access to midwifery professional associations. There are few midwives in many countries posing challenges for ongoing education and succession planning. Midwifery is invisible in much of the regulation and therefore in the acknowledgement of the contribution of midwives. 


\section{INTRODUCTION}

Midwifery is now recognised as a solution to meet global sexual, reproductive, maternal and newborn health goals. ${ }^{1-5} \mathrm{~A}$ highly qualified, competent midwifery workforce in adequate numbers is needed in every country if midwifery is to be effective. The global movement to strengthen midwifery has been supported by the International Confederation of Midwives (ICM) and its partners, including the United Nations Population Fund (UNFPA) and WHO. ICM and others have focused on midwifery education, regulation and professional association (ERA); collectively known as the three pillars of midwifery. ${ }^{6}$

The three pillars provide a framework for countries to strengthen and scale up the production of qualified, professional midwives to achieve the global standards and requirements for high quality maternal and child health services. ${ }^{7}$ ICM have developed standards to support the education and regulation of midwives ${ }^{8,9}$ as well as an assessment tool to assist in strengthening the professional association. ${ }^{10}$ The ICM global standards on education promote competency based education including basic essential midwifery competencies that are aligned with regulatory systems. ${ }^{9}$ The standards on regulation aim to ensure safety of women and children and promote autonomous midwifery practice and there is now a toolkit to assist implementation. ${ }^{8}$ ICM has also developed an assessment tool to support professional associations to strengthen their organizational capacity to act as a leading voice for the profession and advocate for maternal and child health at policy and decision making level. ${ }^{10}$

An assessment of midwifery education, regulation and association occurred in 73 of the 75 Countdown countries as part of the State of the World's Midwifery research in 2013, ${ }^{6,11}$ in six South Asian countries in $2010^{12}$ and more recently in 12 Arab countries. ${ }^{13}$ These analyses showed considerable variations across countries and regions in curricula, faculty development, educational resources and supervised experience in clinical practice and limited legislation that recognised 
midwifery as an autonomous profession. Many countries had access to professional associations although not all were exclusive to midwives.

The only countries included in the State of the World's Midwifery from the South Pacific region were Papua New Guinea and the Solomon Islands. Both countries showed significant shortages in the midwifery workforce and the capacity to respond to the sexual, reproductive, maternal and newborn health needs. ${ }^{2}$ Other than the high income nations of Australia and New Zealand, there are other small island nations in this region -all with their own needs for sexual, reproductive, maternal and newborn health services and a workforce to provide care, yet very little is known about the midwifery workforce in these countries.

\section{The small island nations of the South Pacific}

The small island nations of the South Pacific are characterised by isolated small land areas, division and distance from larger countries and generally small populations. ${ }^{14}$ The geography and low economic status of the region often makes it challenging to provide health services, in particular, isolation makes transport and communication difficult and expensive. ${ }^{15-18}$ Many of the countries have been affected in recent years by a changing climate including heat waves, cyclones and tsunamis, which tend to cripple an already fragile health system and damage the limited infrastructure that exists. ${ }^{16,19}$ Almost all countries in the South Pacific are dependent on overseas aid funding despite aid fatigue and this poses challenges in terms of sustainability and workforce planning and development. ${ }^{17,20}$

The small island nations of the South Pacific are at different stages of the demographic transition, ${ }^{21}$ with some populations still experiencing relatively high mortality and fertility. Assessment of key indicators such as maternal mortality is difficult due to small populations and inadequate data collection systems. ${ }^{17,19,22}$ What is evident though is that there are workforce 
shortages and uneven distribution of the health workforce including midwives, nurses and doctors throughout the countries. ${ }^{16,19}$ The World Bank has undertaken workforce analyses in some of the larger countries, for example in Papua New Guinea. This showed significant shortages in all cadres in the health workforce and highlighted the lack of data in many areas, including midwifery, making an accurate assessment of future needs difficult. ${ }^{23}$

Specifically, in terms of the midwifery workforce across the South Pacific, very little is known. ${ }^{24}$ Midwives are usually counted as nurses and rarely disaggregated at a Ministry of Health level. This means that it is impossible to know the number of midwives in a country or the way they are educated, regulated and professionally supported. Given educated and regulated midwives are the most cost effective health care provider for mothers and newborns, ${ }^{4}$ it is critical to have an in-depth understanding of the midwifery workforce across the countries, especially as only two were included in the State of the World's Midwifery Report. ${ }^{2}$ The aim of this study therefore was to examine the gaps and challenges in the education, regulation and professional associations for midwives in small island nations of the South Pacific.

\section{METHODS}

A multi country descriptive study was undertaken between April-December 2015. The data were collected through a survey to explore the gaps in midwifery pillars across 12 small island nations of the South Pacific. The specific objectives were to:

a) Explore the current situation of midwifery education and competencies in relation to midwifery global standards

b) Identify the process of licensure and re-licensing

c) Describe role of association in each country 
Ethical approval was received for the study from the lead university's' Human Research Ethics Committee. The study was undertaken in partnership with the South Pacific Chief Nursing and Midwifery Officers Alliance (SPCNMOA). The SPCNMOA purpose is to raise the quality of nursing, midwifery and health leadership. The SPCNMOA representatives from 12 small island nations of the South Pacific (Figure 1) were briefed about the study and approved it prior to commencement. It was agreed that the education, regulation and association detail about each country would be anonymized although this was provided back to the individual country.

$<$ Insert Figure 1 here $>$

The survey was based on the larger survey used for the State of the World's Midwifery Report 2014. ${ }^{2}$ The larger survey includes questions about the full health workforce to provide maternal and newborn services. This adapted survey focused on midwives and nurse-midwives or nurses in countries where there were no midwives. Therefore, a sub-section of the questions were used and these were tailored to the region. English was chosen as the language of the questions the selected islands communicate across the region in English. The SPCNMOA were asked to review the content of the survey and changes were made based on their feedback to improve clarity.

The survey included three domain areas, each addressing one of the pillars of education, regulation and association. Specifically, there were questions about workforce, education systems, qualifications and competencies, current situation of midwifery regulation, position of the midwifery association in the country, challenges faced and support received by the government and other stakeholders.

Key country representatives to complete the survey were identified by the SPCNMOA. These were usually the chief nursing and midwifery officer or lead advisor for midwifery in the country. An email 
was sent to each of the key representatives with a copy of the survey and an offer to assist with completion by phone or Skype call. We invited the 12 countries with English as a common language and all agreed to participate. Countries with poor access to internet or email were telephoned and the data were collected by a research assistant. In addition, to ensure consistency and reliability of given information countries were asked to send any other additional related existing data if available, for example, any relevant workforce analyses.

A descriptive data analysis of the quantitative data was conducted. In the tabular analysis (Figure 2), countries have been de-identified to protect privacy as agreed in the ethics approval process. The open-ended responses which produced qualitative data were analysed thematically using a content analysis approach.

\section{FINDINGS}

Twelve small island nations of the South Pacific were invited to participate in this study and all agreed (Figure 1). All 12 countries have categories of health provider called either a midwife, a nurse-midwife or a nurse with midwifery qualifications. For the purposes of simplicity, this paper will refer to midwives and nurse-midwives as 'midwives'.

The number of midwives in each country varied from two (Niue Islands) to 765 (Papua New Guinea). The density of midwives was estimated using the population in each country. The population density of midwives per population ranged from 0.1- 4 per 1000 population (Table 1)

<insert Table 1 here>

All countries reported they have other cadres of providers who provide maternal, newborn and child health $(\mathrm{MNCH})$ care. Registered nurses or enrolled nurses $(100 \%)$ are the most popular $\mathrm{MNCH}$ 
providers in all countries followed by medical officers (general and specialist obstetrician), assistants in nursing and community health workers.

\section{Education}

The minimum requirement to become a midwife was Grade 12 schooling. Being educated as a nurse first was mandatory in all 12 countries. In seven countries, it was also required to have a certain number of years of work experience as a nurse before entering into a midwifery program. This varied across countries from one to five years (Figure 2).

<insert Figure 2 here>

Midwifery education was provided in six of the 12 countries although the length of the course varied. One country provided a program for less than one year (34 weeks), for three countries it was 12 months education and in two countries it was 18 months. None of the countries reported direct entry midwifery program. The countries who did not have a midwifery school required students to receive their education elsewhere - most commonly in Fiji. The annual intake of students varied across countries ranged from 2 (who were sent to another country for education) to 130 (educated in the country).

There were a range of different qualification titles for the midwifery education programs in these six countries from Certificate to Post-Graduate Diploma and Bachelor's degrees. The number of births that students were required to attend prior to being eligible to qualify as a midwife ranged from 20 to 50 . Five of the six countries who had a midwifery school reported using a standardized national curriculum which had been updated in the last 5-8 years.

\section{Challenges facing midwifery education}

Ten countries responded to the open-ended question about the challenges facing midwifery 
education in their country. Lack of qualified teaching staff and difficulties in recruiting sufficient teaching staff were expressed as the most common challenges by almost all 10 countries. Seven countries also reported problems with ongoing professional development and in-service education to ensure teaching staff were up-to-date, as well as lack of teaching space and poor quality of equipment. Half the countries reported high rates of staff turnover and low retention of the midwifery teaching staff. Five countries mentioned that they felt that the curricula did not cover the core midwifery competencies required in their context.

In four countries, the low number of women giving birth and inadequate clinical sites was challenging for students to achieve all the core midwifery competencies. Other challenges reported included the lack of an accreditation system for midwifery education to fulfill educational requirements and a lack of students being prepared for further education.

\section{Regulation}

Six countries reported having a recognised definition of midwifery as a specific cadre of health providers. One of these reported having a definition of midwifery that is not used. The remaining six countries reported that they have no recognised definition but two of those countries have plans to develop it. Five countries reported they have legislation that recognised midwifery as a regulated profession.

Most countries $(n=9 ; 75 \%)$ reported the existence of an authority which has the responsibility to regulate health professionals including midwifery. Five countries reported that the country's Nursing Council or Nursing and Midwifery Council were the responsible body to regulate midwifery; four countries reported that the Ministry of Health was the regulatory authority. The final three countries did not have an identified regulatory body for midwifery. 
ethics, registration, verification, setting standards for practice and continuing professional development were seen as the most common responsibilities. Five countries reported providing advice to the government on maternal, newborn and child health issues; ensuring quality of education and accreditation of education and setting scope of practice for midwives; investigating misconduct and applying sanctions to midwives found to be guilty of misconduct; and, competency assessment prior to registration (44\%). Few countries listed the protection of the professional title as a responsibility of the regulatory body.

Half of countries $(n=6)$ reported that a system of licensing was in place for graduates to be able to start midwifery practice and the register of licensed midwives was electronic in three of these countries. The update of the register varied from monthly to annually. In three of the six countries without a register, there were plans being made to develop one.

Clarity on the scope of practice for midwives was a challenge expressed in the open-ended questions. Midwifery was commonly mixed with nursing making clarity about the role challenging. Most countries expressed their need for separate licensing for midwives and improvement in the regulatory system although few were in the process to include midwifery as separate profession in their legislation.

\section{Professional Association}

Eleven of 12 countries had an established nursing association which also represented midwifery although mostly not as a special interest group. Three countries had specific midwifery associations. Most of those midwifery associations were established between 2005-2015. The number of members ranged from 10 to 200 . Only one of the midwifery associations reported being a member of ICM. The role of the associations was mainly focused on providing continuing professional development, providing advice to midwives on quality standards and undertaking advocacy and negotiations with government on professional matters such as salary. 
Most of the small Pacific Islands found it highly challenging to establish an independent midwifery association as they have small number of midwives. For example:

"With the small number of midwives in the country we cannot form a separate midwifery association as they are part of the Nursing Association".

However, a vibrant midwifery association which advocates for the profession was also considered by some as a vital intervention as explained here:

"I hope we will have a Midwives Association in the near future, because there are lots of important midwifery issues that need to be discussed and activities that need the expertise of midwives only. We definitely would like to have an association soon".

\section{Midwifery as a profession}

The survey asked about the relative attractiveness of midwifery as a profession. Most countries ( $n=10 ; 80 \%$ ) felt that midwifery was an attractive option due to the opportunity for upgrading skills and knowledge and midwives were seen as having more opportunity to move into higher level leadership positions within health systems. Midwifery was regarded as a specialised and highly respected profession by the community as one of the respondents articulated:

"As a qualified midwife you have extra specialty and privilege to work in the remote Islands and communities. There is opportunity to be a leader in a higher position such as charge nurse, nursing supervisor and acting quality manager. It is an honor to be looking after a mother during antenatal, delivery and postnatal care. You become to know the family as a whole".

\section{Challenges and solutions}

Countries were asked to list their three biggest challenges facing midwifery. The shortage of midwifery workforce was mentioned by most countries. In addition, the low quality of midwifery 
education and lack of opportunities for continuing professional development and inadequate qualified midwives to take up key decision-making and leadership roles were also seen as significant challenges.

Most countries acknowledged the need for ongoing professional development and quality improvement of midwifery education especially the review and revision of existing curricula. Establishment and/or improvement of midwifery associations were considered as important strategies to advocate for midwifery matters at policy level. One of the countries suggested that the development of regional midwifery competencies would be beneficial especially for the smaller countries.

An urgent need to increase the midwifery workforce to address maternal and child health issues was among the most important solution to the challenges mentioned by all countries. For example:

"Improvement in midwifery education is a priority and discussion has been ongoing within educational institutions and industry. The need for more midwives for the improvement of child health and maternal services remains as a top agenda".

\section{DISCUSSION}

This survey describes the current status of midwifery in 12 small island nations of the South Pacific which are amongst the lowest to middle income countries in the Asia Pacific region. There were considerable shortages of midwives identified in all countries although this was more accentuated in the larger countries. Similarities across the countries included a requirement for midwives to be nurses. Differences included the level of education program, length of education, clinical requirements and access to local educational institutions. The regulation of midwifery varied across the countries with differences in legislation recognising midwifery and in the registration of midwives. Few countries had a specific professional association for midwives or specific interest 
groups within the nursing associations.

Midwives, especially in low resource settings, are the frontline care providers and need to be well educated and adequately regulated to address maternal and newborn health needs ${ }^{4,5}$ and provide universal health coverage.$^{25}$ There have been efforts in the past decade to support the increase in the numbers of doctors, nurses, midwives and community health workers in the South Pacific region ${ }^{26}$ but these have not been sufficient to date. Globally, there is a recognition that investment in the health workforce has been low, leaving gaps between demand and supply, problems with retention and distribution and a lack of commitment towards health professional education. ${ }^{27}$ Midwives are equally affected by these challenges. Other disciplines in the South Pacific region have recognised that human resources and leadership are some of the critical elements to close the gap in child health. ${ }^{28}$ It is likely that to close the maternal and newborn gaps, similar approaches are needed for midwifery.

The State of the World's Midwifery Report (SoWMy) focused on 73 of the 75 low- and middleincome countries including Papua New Guinea and the Solomon Islands. ${ }^{2}$ This report provided evidence to support the dialogue between governments and stakeholders, acceleration of the progress to Millennium Development Goals (MDGs) and contribution to the post-2015 development agenda. Overall, it found more than $92 \%$ of all the world's maternal and newborn deaths and stillbirths occur within these 73 countries, however, only $42 \%$ of the world's midwifery, medical and nursing personnel are available to women and newborns in these countries. In PNG, it was estimated that the current midwifery workforce only met $49 \%$ of the estimated need and, in the Solomon Islands, only $33 \%$ of the estimated need was met. SoWMY included other cadre in the calculation of the midwifery workforce including nurses and community health workers as these cadre play a significant role in the provision of maternal and newborn health services. Our analysis has just focused on midwives and it is likely that the proportion of estimated met need would be 
considerably lower, again highlighting the critical need for midwives across the region. A regional midwifery workforce strategy, building on the new global strategies ${ }^{29}$ would be an important approach for the countries in the region, especially the smaller ones.

Providing midwifery education in these countries is not without challenges and is a similar challenge for other disciplines such as medicine and child health. ${ }^{30}$ The cost associated with midwifery education is one barrier as students in some countries had to undertake midwifery education in other countries. These smaller countries faced problems with capacity as there were few nurses who could be sent away to do midwifery and succession planning was difficult. Previous research has also shown that most midwifery education systems were struggling to provide a quality of education based on international standards. ${ }^{24}$ Over the past 20 years, there have been significant shifts in many low, middle and high income countries in relation to the education of midwives from a postgraduate nursing program to consider alternative pathways including a direct entry model. ${ }^{31-33}$ In the 73 SoWMy countries, direct-entry education programs for midwives were reported by 53 (73\%) countries, including Bangladesh, Timor Leste and Indonesia. ${ }^{2}$ There are no direct entry programs in the 12 countries surveyed for this study with all midwifery education occurring after registered nurse education. One of the challenges associated with the current midwifery education model in this region is that educating students directly depletes the nursing workforce as students of midwifery must be registered nurses. It may be useful to explore new ways to educate midwives, especially in the larger countries where the sexual, reproductive, maternal and newborn health needs are considerable. A direct entry midwife in many countries caters for all the sexual, reproductive, maternal, newborn and child health needs and in some countries, a 'cradle-to-grave' scope of practice is utilised which includes older women's health care including menopause. This will extend beyond the ICM International Definition of the Midwife. ${ }^{34}$ The models of care and the way the systems are arranged and the staff deployed would need to be addressed especially in rural areas for this type of model to be sustainable and to ensure that the midwife was effectively utilised. 
Models like this may not work in all countries but deserve consideration, especially in larger settings. A regional approach to midwifery education or shared principles in midwifery education may also enable support to be provided between the countries and build capacity in the midwifery faculty across these countries to ensure that quality graduates are produced regardless of their educational pathway. ${ }^{35}$

The results draw a picture of the current situation in the small island nations of the South Pacific. Migration continues to be a major challenge in many small island nations and this compounded by small populations and challenges with infrastructure, communication and the impact of climate change add to the complexities. ${ }^{16,20}$ Addressing education, regulation and association amongst such challenges needs new ways of thinking in order to reduce maternal and child mortality. ${ }^{11}$. The pillars are interdependent and if any are weak, the midwifery profession is weakened at all levels.

Education must not only include 'entry-to-practice but also access to continuing professional development (CPD). Research in Papua New Guinea has shown that midwives lack ongoing access to $\mathrm{CPD}^{36,37}$ and this is also reported for child health nurses in the Solomon Islands. ${ }^{30}$ Education, both initial and CPD is an important avenue to build and maintain quality care and ensure that health staff are continually refreshed and motivated to provide effective care.

Regional workforce planning, including a commitment to common regulatory standards and a shared professional association for midwives, may assist in the ongoing development of the profession across the region. In other regions, midwifery associations represent a key provider group in sexual, reproductive, maternal and newborn health and as such have a significant capacity to contribute to policy development and planning and make a meaningful contribution to the achievement of the goals of universal health coverage. ${ }^{6}$ The International Confederation of Midwives now enables a region to be considered a member rather than individual countries. This may provide opportunities 
for smaller countries to come together to create a midwifery association that could provide midwifery leadership, visibility and support.

The lack of a combined midwifery voice within, and across, many countries such as these in the South Pacific poses significant problems in terms of visibility and identity. Earlier research in Australia has identified barriers for the development of midwifery as a profession and for maternity services more broadly. These included the lack of visibility of midwives, especially in regulation. ${ }^{38,}$ Regulation is built upon legislation, establishing the set of criteria and processes that supports midwives to work within their full scope of practice. If there is no legislation to support regulatory activities, the recognition and scope of action of midwives can be limited and inefficient, even if the government is the main regulator. Where midwives are not identified in regulatory frameworks or in legislation, visibility and the opportunity to contribute meaningfully to the policy debate and future directions are often limited. Given, few countries in this survey had strong regulatory frameworks for midwifery, ongoing efforts need to be made to ensure visibility as this will support the safety of the public in terms of the provision of quality care.

\section{Conclusion}

This is the first time a survey of the 12 small island nations of the South Pacific has been with a focus on the midwifery workforce. Across the countries there were shortages of midwives identified especially in larger countries. Differences included the level of education program, length of education, clinical requirements and access to local educational institutions as well as the regulation of midwifery across the region. Few countries had a specific professional association for midwives or specific interest groups within the nursing associations.

Future workforce development and opportunities in the region need to consider the analysis presented here and develop creative ways to support small island nations, especially those with 
small populations and geographical challenges. A strong and effective midwifery profession is important to address maternal and newborn health and all countries, small and large, need support to ensure the provision of quality midwifery care to assure the health of their communities. 
Figure1: Map of the South Pacific Island region with the participating countries circled

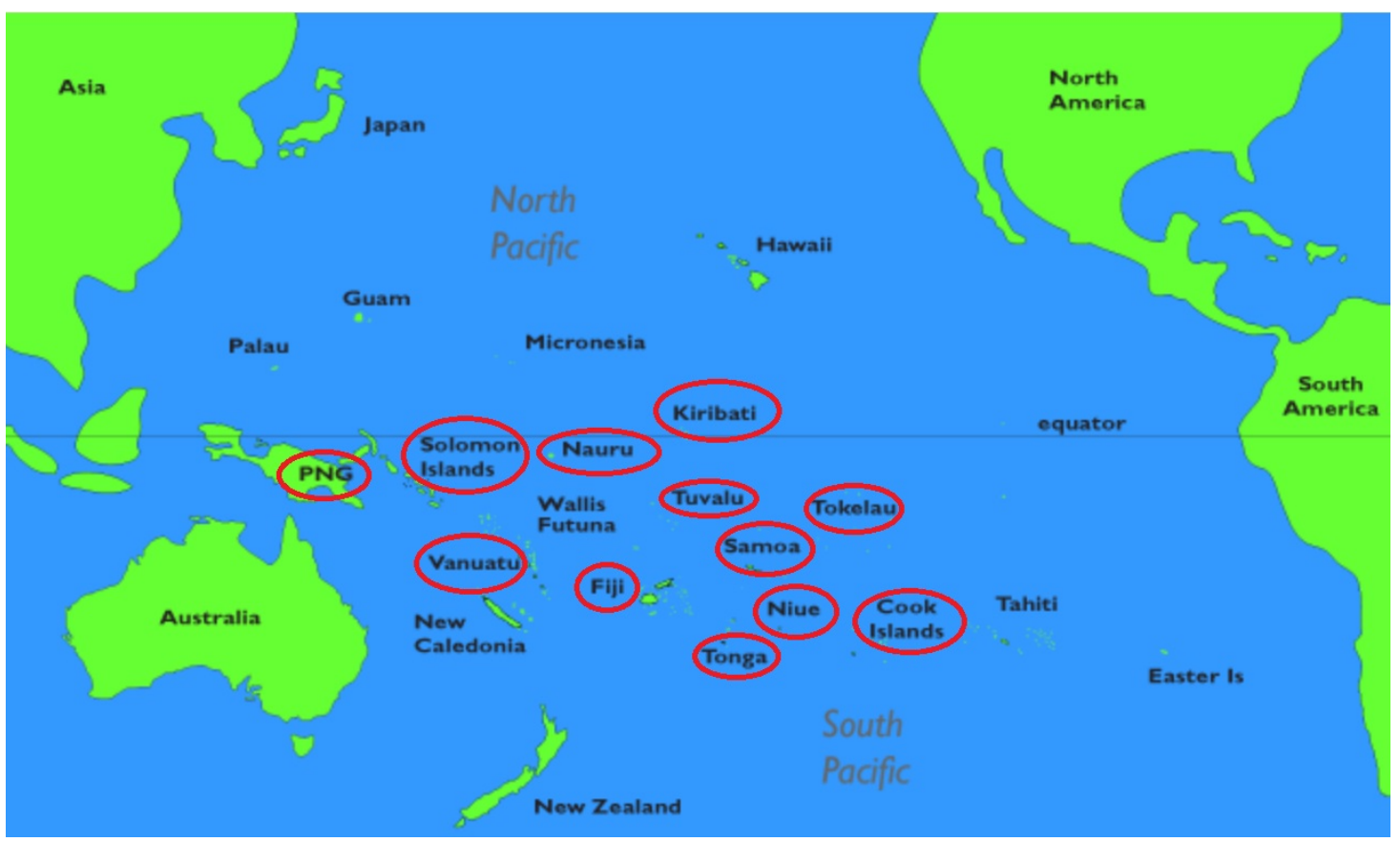


Table 1: Population density of midwives to population

\begin{tabular}{|lccc|}
\hline Country & Total population & $\begin{array}{c}\text { Number of } \\
\text { midwives* }\end{array}$ & $\begin{array}{c}\text { Midwives population density (per } \\
\text { 1000 population) }\end{array}$ \\
\hline PNG & $6,700,000$ & 765 & 0.11 \\
\hline Fiji & 854,000 & 350 & 0.41 \\
\hline Solomon Islands & 552,267 & 120 & 0.22 \\
\hline Vanuatu & 245,619 & 56 & 0.23 \\
\hline Samoa & 184,032 & 60 & 0.33 \\
\hline Kiribati & 103,466 & 118 & 1.14 \\
\hline Tonga & 103,365 & 20 & 0.19 \\
\hline Cook Islands & 23,300 & 38 & 0.90 \\
\hline Tuvalu & 11,149 & 10 & 0.50 \\
\hline Nauru & 9,976 & 5 & 1.34 \\
\hline Niue & 1,496 & 2 & 2.83 \\
\hline Tokelau & 1,411 & 4 & \\
\hline
\end{tabular}

*Number reported at time of survey completion (late 2015) 
Figure 1: Graphical representation of midwives by population in $\mathbf{1 2} \mathrm{small}$ island nations of the South Pacific

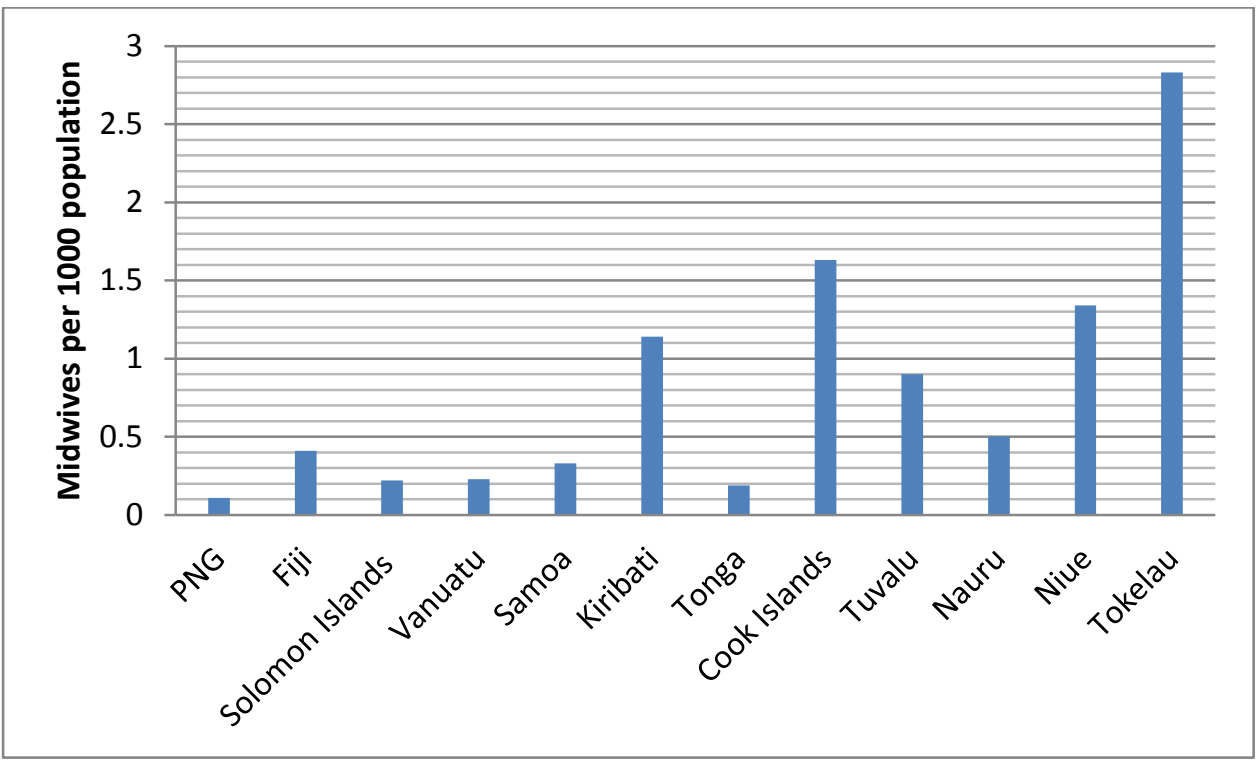


1 Figure 2: Mapping of education, regulation and association across 12 countries

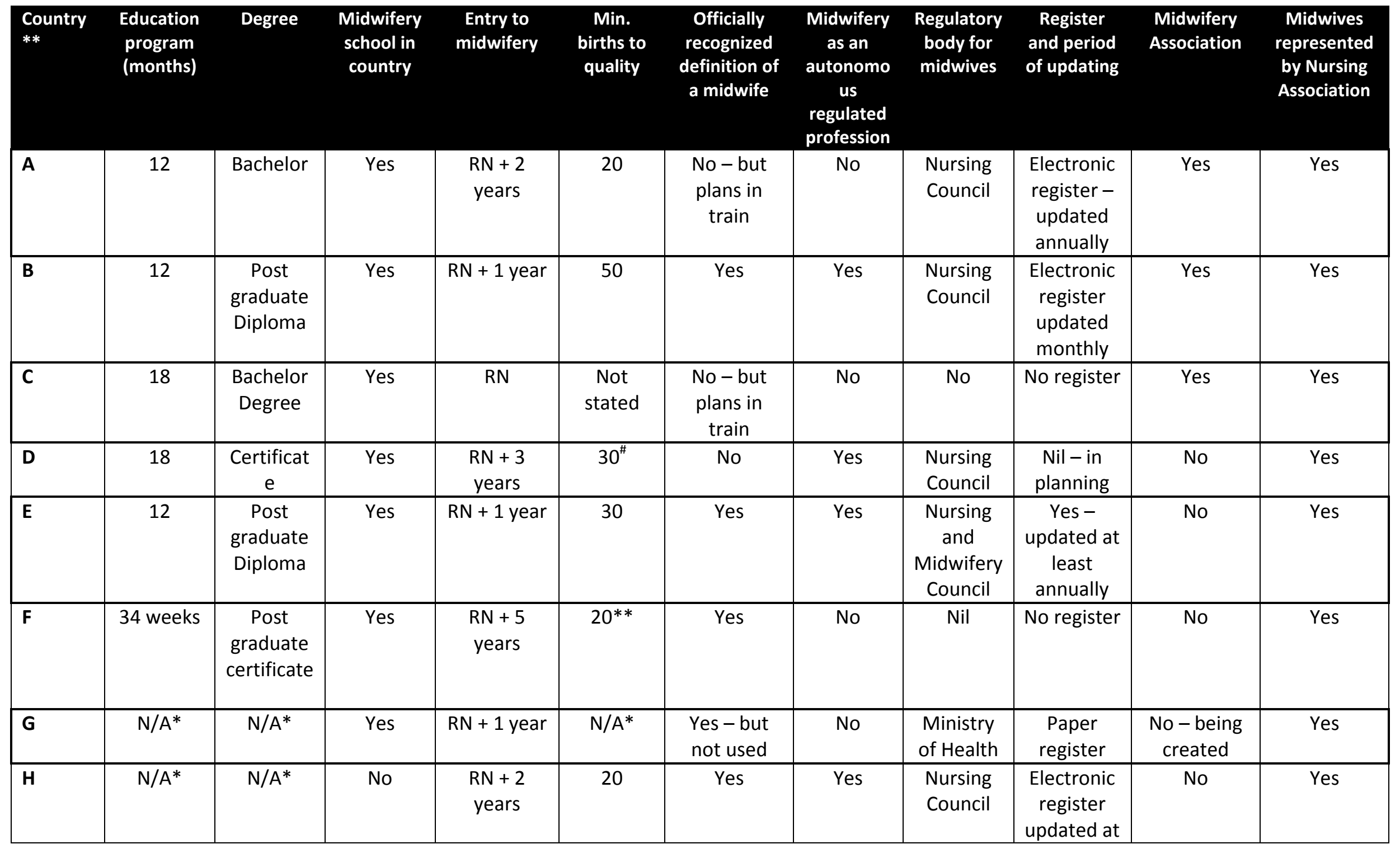




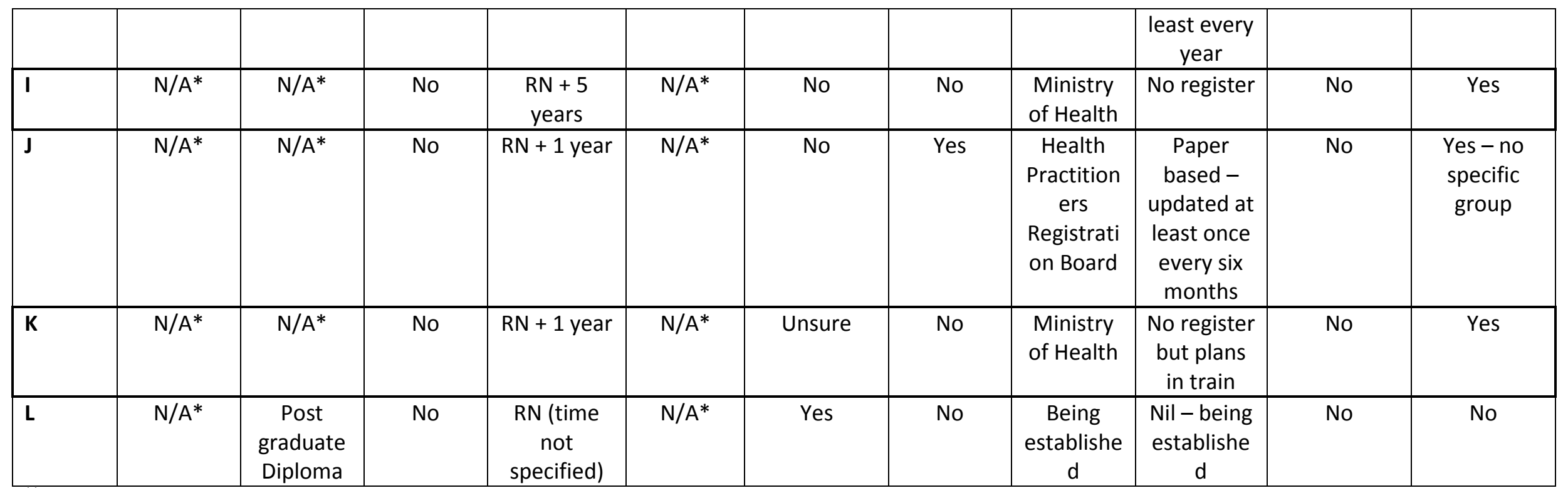

"The countries are not identified to protect confidentiality. The data are displayed to show the variance across the region. Each letter represents a country.

3 these countries sent students to other countries for midwifery education

$4 \quad \# 20$ normal, 5 breech, 5 complex births

$5 * * 10$ normal, 10 abnormal 


\section{References}

1. United Nations Population Fund. The State of the World's Midwifery Report. New York: United Nations Population Fund; 2011.

2. United Nations Population Fund, International Confederation of Midwives, World Health Organization. State of the World's Midwifery. Barcelona: UNFPA, ICM and WHO; 2014.

3. Homer C, Friberg I, Dias M, et al. The projected effect of scaling up midwifery. The Lancet 2014; 384: 1146-57.

4. Renfrew $M$, McFadden $A$, Bastos $H$, et al. Midwifery and quality care: findings from a new evidence-informed framework for maternal and newborn care. The Lancet 2014; 384: 1129-45.

5. ten Hoope-Bender $\mathrm{P}$, de Bernis $\mathrm{L}$, Campbell J, et al. Improving maternal and newborn health through midwifery. The Lancet 2014; 384: 1226-35.

6. Lopes S, Titulaer P, Bokosi M, Homer C, Ten Hoope-Bender P. The involvement of midwives associations in policy and planning about the midwifery workforce: A global survey. Midwifery 2015; ;31:1096-103.

7. International Confederation of Midwives. Education, Regulation and Association. 2016. http://www.internationalmidwives.org/what-we-do/education-regulationassociation/ (accessed 20 August 2016). The Hague, International Confederation of Midwives, 2014.

8. International Confederation of Midwives. Midwifery Regulation Toolkit. The Hague: International Confederation of Midwives; 2016.

9. International Confederation of Midwives. Global Standards for Midwifery Education The Hague: International Confederation of Midwives; 2013.

10. International Confederation of Midwives. The Member Association Capacity Assessment Tool (MACAT) The Hague: International Confederation of Midwives; 2011.

11. Lopes $\mathrm{S}$, Nove A, ten Hoope-Bender $\mathrm{P}$, et al. A descriptive analysis of midwifery education, regulation and association in 73 countries: The baseline for a post-2015 pathway. Human Resources for Health 2016; 14: 37. 
12. Bogren $M$, Wiseman $A$, Berg $M$. Midwifery education, regulation and association in six South Asian countries; A descriptive report. Sexual \& Reproductive Healthcare 2012; 3(2): 67-72.

13. United Nations Population Fund. Analysis of the midwifery workforce in selected Arab countries (UNFPA). New York: United Nations Population Fund; 2015.

14. Lewis N, Rapaport M. In a sea of change: health transitions in the Pacific. Health \& Place 1995; 1(4): 211-26.

15. Fletcher S, Thiessen J, Gero A, Rumsey M, Kuruppu N, Willetts J. Traditional Coping Strategies and Disaster Response: Examples from the South Pacific Region. Journal of Environmental \& Public Health 2013: 1-9.

16. Rumsey $M$, Fletcher $S$, Thiessen J, et al. A qualitative examination of the health workforce needs during climate change disaster response in Pacific Island Countries. Human Resources for Health 2014; 12: 1-11.

17. United Nations Population Fund. Achieving Universal Access to Reproductive Health Services \& Commodities; and The Pacific Policy Framework 2008 - 2015, (Report: 978-982-520-047-5). Suva, Fiji: UNFPA; 2008.

18. Binns C, Hokama T, Low W. Island Health: Hope and Challenges for Public Health. Asia-Pacific Journal of Public Health 2010; 22(1): 19-24.

19. Yamamoto T, Sunguya B, Shiao L, Amiya R, Saw Y, Jimba M. Migration of Health Workers in the Pacific Islands: A Bottleneck to Health Development'. Asia-Pacific Journal of Public Health 2012; 24: 697-709.

20. Connell J. Pacific islands in the global economy: Paradoxes of migration and culture. Singapore Journal of Tropical Geography 2010; 31(1): 115-29.

21. Slade T. A strategy to support development in the Pacific. International Trade Forum 2013; 3: 26-7.

22. Taylor R, Lopez A. Contemporary patterns of Pacific Island mortality. International Journal of Epidemiology 2005; 34: 207-14.

23. World Bank. PNG Health Workforce Crisis: A Call to Action. New Hampshire: World Bank; 2011.

24. Usher K, Stewart L, West C, et al. Enhancing the quality of nursing and midwifery; Educational Programs and Services in the Pacific. Townsville: James Cook University and Auckland University of Technology; 2012. 
25. Dawson A, Nkowane A, Whelan A. Approaches to improving the contribution of the nursing and midwifery workforce to increasing universal access to primary health care for vulnerable populations: a systematic review. Human Resources for Health 2015; 13(1): 1-23.

26. World Health Organization. Strategic Action Plan for Nursing and Midwifery Development in the Western Pacific Region. Manila: World Health Organization; 2006.

27. Global Health Workforce Alliance. A Universal Truth: No Health Without a Workforce. Geneva: World Health Organization; 2013.

28. Duke T, Kado J, Auto J, Amini J, Gilbert K. Closing the gaps in child health in the Pacific: An achievable goal in the next 20 years. Journal of Paediatrics and Child Health 2015; 51(1): 54-60.

29. World Health Organization. Global strategic directions for strengthening nursing and midwifery 2016-2020. Geneva: World Health Organization; 2016.

30. Colquhoun S, Ogaoga D, Tamou M, Nasi T, Subhi R, Duke T. Child health nurses in the Solomon Islands: lessons for the Pacific and other developing countries. Human Resources for Health 2012; 10(1): 1-9.

31. Fullerton J, Johnson P, Thompson J, Vivio D. Quality considerations in midwifery preservice education: Exemplars from Africa. Midwifery 2011; 27: 308-15.

32. Leap N, Barclay L, Sheehan A. Results of the Australian Midwifery Action Project Education Survey. Paper 2: Barriers to effective midwifery education as identified by midwifery course coordinators. Australian Midwifery Journal 2003; 16(3): 6-11.

33. World Health Organization. Global standards for the initial education of professional nurses and midwives. Geneva: World Health Organization; 2009.

34. International Confederation of Midwives. International Definition of a Midwife. 2011. http://www.internationalmidwives.org/who-we-are/policy-and-practice/icminternational-definition-of-the-midwife/ (accessed 21 February 2017). The Hague, International Confederation of Midwives.

35. West F, Homer C, Dawson A. Building midwifery educator capacity in teaching in low and lower-middle income countries. A review of the literature. Midwifery 2015. 
100 36. Moores A, Catling C, West F, et al. What motivates midwifery students to study midwifery in Papua New Guinea? . Pacific Journal of Reproductive Health 2015; 1(2): 60-7.

103 37. Moores A, Puawe P, Buasi N, et al. Education, employment and practice: Midwifery graduates in Papua New Guinea. Midwifery 2016; 41::22-29.

105 38. Brodie P. Addressing the barriers to midwifery: Australian midwives speaking out. Journal of the Australian College of Midwives 2002; 15(3): 5-14. 